\title{
Major challenges facing teacher counselors in schools in Namibia
}

\author{
John Mushaandja ${ }^{1,}$, , Cynthy Haihambo ${ }^{2}$, Tania Vergnani ${ }^{3}$, Elzan Frank ${ }^{4}$ \\ ${ }^{1}$ Department of Educational Foundations and Management, University of Namibia, Windhoek, Namibia \\ ${ }^{2}$ Department of Educational Psychology and Inclusive Education, University of Namibia, Windhoek, Namibia \\ ${ }^{3} \mathrm{HIV}$ and AIDS Programme, University of the Western Cape, Bellville, South Africa \\ ${ }^{4}$ Child and Family Unit, University of Stellenbosch, Matieland, Stellenbosch, South Africa
}

\section{Email address:}

jmushaandja@unam.na(J.Mushaandja)

\section{To cite this article:}

John Mushaandja, Cynthy Haihambo, Tania Vergnani, Elzan Frank. Major Challenges Facing Teacher Counselors in Schools in Namibia. Education Journal. Vol. 2, No. 3, 2013, pp. 77-84. doi: 10.11648/j.edu.20130203.13

\begin{abstract}
There was a significant number of learners in Namibian schools whose psycho-social circumstances were dire as a result of a variety of socio-economic, psychological and cultural factors. The learners needed psycho-social support. Instead of appointing qualified school counselors, the Ministry of Education directed schools to appoint teacher counselors (lay counselors) to render this support. Teacher counselors are teachers who are entrusted with the responsibility of rendering lay counseling services to learners in the school setting. Some teachers volunteered to become teacher counselors, others were elected by their fellow teachers, and others were nominated by their principals because they had lighter workloads or were doing work that was related to counseling. This study attempted to identify the major challenges facing the teacher counselors. The study made use of a qualitative approach. Forty nine teacher counselors from 18 primary and secondary schools in three regions constituted the sample. The data collection instruments were documentary analysis, individual interviews, focus group discussions/interviews, and informal interactions. Many teacher counselors were committed and motivated to make psycho-social interventions and acted as advocates for the learners. In many schools, little (if any) real counseling took place; most interventions were practical and/or focused on motivating learners not to become disheartened. The study revealed that the teacher counselors were facing many challenges including unavailability of appropriate space and time to counsel learners, and lack of skills to effectively address learners' psychosocial needs. The teacher counselors recommended, inter alia, that they be appointed full time, and that principals should attend counseling training so that they understand and support teacher counselors.
\end{abstract}

Keywords: Namibia, Teacher Counselors, Counseling, Psycho-Social Support

\section{Introduction}

In terms of the Education sector policy for orphans and vulnerable children [1], learners at all schools should have access to psycho-social support, provided by teachers who have been trained as teacher counselors. With the financial support of the Global Fund, training and support systems have been implemented to build capacity in schools with the aim that schools should operate as "units of social support" providing "pastoral care and guidance" [2, p. 5]. This study is an evaluation and assessment of the counseling services provided at schools by teacher counselors. The evaluation was done in three of the thirteen regions in Namibia: Khomas, Kunene and Oshana. Considering the financial limitations that prevented the evaluation from being conducted in all thirteen regions, these three regions were sampled by the Ministry of Education as representative of national, cultural and sociological characteristics of all other Namibian regions. Before this study, there hasn't been any formal evaluation of the counseling services provided to learners in schools in Namibia. Existing literature reveals that most studies that included the element of counseling in schools assessed this from the perspective of orphans and vulnerable children, and not from perspective of teacher counselors $[3,1]$. The objective that guided this study was to identify the major challenges facing teacher counselors in schools in three regions in Namibia. 


\section{Contextualizing the Teacher Counselor in the Namibian Education System}

In the Ministry of Education system in Namibia, a teacher counselor was a teacher in a primary or secondary government school who has been entrusted with the responsibility of rendering counseling or any type of psychosocial support to learners within a school setting. Teacher counselors were appointed by school management based on their characteristics, subject areas or workload. The position of the teacher counselor was voluntary (in the sense that one volunteers or agrees to assume this role) in nature and although it was expected of each government school to have teachers performing this role. The position was not on the official staff establishment and therefore no incentives were attached to it.

The counseling rendered by teacher counselors followed a para-professional model, as the teacher counselors were not qualified school counselors and were not registered with the Health Professional Association of Namibia. They were primarily teachers with a full teaching load and other related responsibilities. Counseling was an additional duty that was treated in the same way as extra-curricular activities such as sport and recreation activities, remedial as well as faith-based activities.

Each school was expected to appoint two or more teachers to serve as teacher counselors. Once appointed, these volunteer counselors were expected to attend training organized by Regional School Counselors as well as Senior School Psychologists in the Ministry of Education. In some training workshops, qualified experts in certain specialization areas were requested by the Ministry of Education to present aspects of the training. A cascade training approach was used, with the trained teacher counselors expected to pass on the training content to other teachers at their schools, and especially to members of the counseling support group, who had not yet attended any of the five sets of training offered. In addition, they were expected to directly or indirectly influence school management regarding psychosocial needs of learners and handling other issues that were likely to result in emotional and behavioral difficulties of learners. Yet, in most schools, given the examination and result-driven education system, schools rarely created time for the transfer of this newly acquired knowledge to staff members who did not attend the training.

\section{Literature Review}

There seems to be a universal consensus that counseling of learners is or should be an essential service in schools in order to reduce the adverse impact of psychosocial problems on the emotional well-being and academic performance of learners. Also it is becoming a common practice that counseling is an added responsibility of teachers. Although every teacher can conduct some counseling of some sort, universities and institutions responsible for the preparation of teachers offer courses relevant to school counseling. There is research evidence [e.g., 4, 5, 6] suggesting that school counseling is a much-needed service in schools. The majority of teachers are supportive of counseling services, because they "see it as a means of ensuring an orderly school community, where the role of the counselor is to smooth out any emotional or behavioral disruptions" [6, p. 209], and to help learners "overcome difficult and challenging life circumstances and risk factors" [7, p. 575). School counseling attends to learners' educational, vocational, emotional, social and personal development [8]. School counselors have to provide information on counseling to parents and school authorities to facilitate informed planning and policy making. Learners bring to school barrages of psycho-social problems such as family break up, abuse and teenage pregnancy, and losses of parents and significant caregivers which require the services of school counselors to decrease the intensity of trauma which interferes with learning and emotional well-being. Despite the school being the only possible premise from which many learners can access psychosocial support without financial implications, learners had various opinions regarding school-based counseling. Whiston and Sexton [4] conducted a review of school counseling outcome research published between 1988 and 1995 and found that counseling services have positive influence on learners. Howieson and Semple [5] found that although learners support school-based counseling, their experience of it differed from its stated aims. In Howieson and Semple's study [5] learners were concerned that school counselors would not maintain confidentiality, a critical aspect that goes with counseling.

The world is ever changing socially, politically and economically. At times these changes impact negatively on learners in many ways, which in turn present challenges to school counselors. While there may be what some people regard as universal challenges facing school counselors, most of the challenges are context bound. The challenges are embedded in the culture of a school and/or community. Thus in order to understand the challenges facing school counselors, there is a need to consider the context in which school counselors offer their counseling services [9].

Paisley and McMahon [9] and Sears and Granello [10] list a number of challenges facing school counselors. Some of the common challenges are: (a) Ongoing debate over role definition of school counselors. At times there is no clear agenda for school counseling. Should they focus on at-risk learners, school violence, learners in the midst of trouble, academic achievement, or all these and many more? Whiston and Sexton [4] recommend that counseling services should focus more on preventative interventions rather than remediation activities. (b) Leaners require diverse counseling services, and the ratio of school counselors to learners is extremely high that counselors may not be accessible to all learners needing their services. (c) The need to use technology to improve counseling services. For example, many school counselors report lack of expertise in using computers to provide services. (d) Calls for school 
counselors to be accountable and demonstrate that they are effective and efficient in their wok. (e) The unavailability of adequate funds challenges school counseling programs to their limits. (f) School counselors do not receive the support of administrators and teachers. One of the reasons for administrators and teachers not to give the necessary support is that they do not have sufficient information on counseling. It is only when administrators and teachers have sufficient information that they will have positive views and true expectations on counseling and give counselors the necessary support.

Because of ever-changing social and cultural climates, school counselors are faced with new goals, tasks and challenges. Consequently, Rayle [11] reports that job-related stress and job dissatisfaction are high among school counselors in the United States of America. Employees without higher job satisfaction are unlikely to increase their commitment. Job dissatisfaction and professional burnout are products of excessive job stress [12]. People in professional positions are likely to experience higher level of exhaustion, alienation from work and desensitization and consequent burn-out; and a counselor who experiences these problems cannot provide counseling services adequately [8]

School counselors should have positive characteristics and adequate pre-service and in-service training. Paisley and McMahon [9] suggest that school counselors should see challenges as opportunities. In order for the challenges to be transformed into opportunities, school counselors and school supervisors should, inter alia, "determine appropriate roles and areas of program focus, design and engage in necessary professional development, and demonstrate accountability for outcomes" [9, p. 6]. If counseling services are to improve significantly, school counseling should be transformed and school counselor preparation programs must change first. Sears and Granello [10] argue that:

"Practicing counsellors must be encouraged to establish a professional identity, to join counselling organizations, and to work with their administrators to help administrators understand and support the importance of professional development for school counselors ... Today's schools require counsellors with the skills to lead change in systems, to collaborate with key stakeholders, to coordinate programs designed to improve student achievement, to use data and technology to promote change, and to advocate for all students ..."

In Namibia, teacher counselors are appointed from a pool of ordinary teachers. Most of the teachers are trained at the University of Namibia (Unam) which is the only institution responsible for the training of teachers. In the B. Ed curriculum, counseling issues are handled in all four years through the following modules [13]:

Table 1. Guidance and counseling courses in the current B Ed degree at UNAM

\begin{tabular}{|c|c|c|c|c|}
\hline Module & Compulsory/ elective & Year of study & Semester & $\operatorname{Aim} / \mathbf{s}$ \\
\hline $\begin{array}{l}\text { Contemporary } \\
\text { Issues }\end{array}$ & Compulsory & 1 & 1 & $\begin{array}{l}\text { Provides teacher trainees with important base of } \\
\text { understanding that can be applied to counseling. }\end{array}$ \\
\hline $\begin{array}{l}\text { Human Development and } \\
\text { Learning }\end{array}$ & Compulsory & 2 & 2 & $\begin{array}{l}\text { Introduces teacher trainees to selected theories of human } \\
\text { development and learning. }\end{array}$ \\
\hline $\begin{array}{l}\text { Introduction to inclusive } \\
\text { Education }\end{array}$ & Compulsory & 2 & 2 & $\begin{array}{l}\text { Introduces teacher trainees to educational needs of } \\
\text { learners and responses to those needs. }\end{array}$ \\
\hline $\begin{array}{l}\text { Introduction to Guidance } \\
\text { and Counseling }\end{array}$ & Compulsory & 3 & 2 & $\begin{array}{l}\text { Sensitizes teacher trainees to educational and career } \\
\text { needs of learners and equip them with basic know-how } \\
\text { and skills regarding guidance and counseling. }\end{array}$ \\
\hline Guidance \& counseling & Elective & 4 & $1 \& 2$ & $\begin{array}{l}\text { Sensitizes teacher trainees to social and psychological } \\
\text { needs and develop their guidance and counseling } \\
\text { know-how and skills }\end{array}$ \\
\hline Inclusive Education & Elective & 4 & $1 \& 2$ & $\begin{array}{l}\text { Enables teacher trainees to understand and apply the } \\
\text { latest thinking in inclusive education. }\end{array}$ \\
\hline
\end{tabular}

It is clear from the table that student teachers are not adequately trained in school counseling, they are only "introduced" or "sensitized" into issues related to counseling. The courses were too theoretical and crowded [2].

The Regional and Assistant Regional School Counselors offer in-service training to teacher counselors once they have been appointed. The following courses are offered: (a) Basic Counseling Skills, (b) Processes of Counseling, (c) Counseling for special difficulties, (d) Bereavement Counseling, (e) Identification of and support of OVC. This training is based on a simple model of "listening well", which only helps teacher counselors to develop understanding and compassion, but it is not sufficient to sustain and enhance resilience and psychosocial competence in learners. Thus, teacher counselors did not have professional qualifications in school counseling, and the pre- and in-service training they receive were inadequate.

\section{Methodology}

This study made use of qualitative methods. This was because the focus was on ensuring that 'rich' data was gathered. The voices of the teacher counselors, as the providers of the counseling services, were given prominence. 
The following data collection methods were utilized: documentary analysis, individual interviews, focus group discussions/interviews, and informal interactions (interviews were comprised both open-ended and close-ended questions). The population for this evaluation comprised all primary and secondary school teachers rendering counseling services to learners in both primary and secondary schools, both in rural and urban settings in Khomas, Kunene and Oshana regions. The school sample comprised 20 schools, of which 2 were used for the pilot study (only in the Khomas region), and 18 for the main evaluation in the Khomas, Kunene and Oshana regions (6 schools per region), and included both rural and urban schools. In each region three secondary and three primary schools were selected through purposive sampling [14]. The sampling was informed by the situation of particular schools at the time prior to, or during data collection. The schools were selected based on two criteria, namely those schools with learners with more psychosocial problems, and had teacher counselors. Each school sub-sample comprised of teacher counselors.

\section{Results}

\subsection{Reasons for Assuming Teacher Counselor'S Role}

A total number of 49 teacher-counselors participated in the study on which this article was based. The teacher counselors were asked to explain reasons why they became teacher counselors. Most teacher counselors took on the role because they were committed to helping learners and cared about their wellbeing. A teacher counselor at a Khomas rural secondary school said, “... being a teacher counselor helps me to help learners help themselves, and this gives me great satisfaction". It is well documented [e.g. 12] that job satisfaction motivates workers to perform to the best of their abilities. Some teacher counselors, however, revealed that they became teacher counselors either due to their lower workloads or because they were already doing something that could easily be linked to a counseling function such as being the Life Skills teachers or working on an HIV and AIDS related program. Some of the teacher counselors landed in this role due to the trust their school principals had in them. There was a correlation between the reason for assuming the role of teacher counselor and the performance of teachers in this role, with those who did not willingly offer counseling services expressing more frustration and being negatively viewed by learners.

\subsection{Key Successes of Teacher Counselors}

Many of the teacher counselors managed to provide much needed support and helped learners experiencing difficulties in their schools cope and sometimes overcome challenging life situations. In general, they were passionate about their work and were selected because they liked to help and were perceived as empathic and approachable. A minority of teacher counselors were in the post because they had lighter workloads or were nominated by their principals or other staff members, without necessarily wanting to do the work.

Committed teacher counselors in many cases succeeded in offering psychosocial support to learners. There was no doubt that some teacher counselors, especially those who were committed to this task, offered much needed psychosocial support to learners. Some teacher counselors carried out duties normally performed by (or expected of) social workers, lawyers, religious leaders and psychologists They identified learners' emotional needs; listened to them; devised feasible interventions and were trusted by the learners. They were also able to offer ongoing support, despite their heavy workloads. The support they offered ranged from basic needs provision (using their own resources to provide learners with food, soap, shelter, etc.); psychological needs (comforting those experiencing problems related to losses of parents and caregivers, adolescent relationships and stigma due to parents socio-economic or medical conditions) and self-actualization needs (finding themselves in a confused world). Despite limited professional qualifications in counseling, many of the teacher- counselors recorded high success rates. In one particular secondary school in the Khomas region, the researchers witnessed how a former learner handed an expensive gift to her former teacher counselor, thanking her for the role she played in her life during the difficult time she went through almost right through her secondary school phase.

\subsection{Major Challenges of Teacher Counselors}

The teacher counselors who participated in this study were facing many challenges. The challenges are grouped in the following categories.

\subsubsection{Lack of Trust or Belief in Counseling by Learners}

Teacher counselors revealed that although they had some skills and were ready to counsel learners, there were cases in which learners did not trust them and did not disclose their problems to them. The teacher counselors attributed the lack of trust to learners' cultures and also parental influence. There were parents who told their children not to discuss private and domestic issues with outsiders (including teacher counselors). This happened despite the fact that families rarely created opportunities for learners to express their problems and have them addressed. Parental perceptions regarding counseling, especially their equation of seeking counseling to "hanging dirty linen" or "embarrassing the family" contributed to learners' reluctance to confide in their teacher counselors. A teacher counselor from a primary school in a Khomas rural area school related an incident in which a pregnant learner refused to open up to her:

"Learners do not trust us. Some parents claim that we teach their children about sex and turn children against the teachers. Culture prescribes that we don't talk about sex related issues with learners, yet pregnancies are occurring even in our school which is a primary school. In this one case, we learned through the nurse that the particular learner was pregnant. When we heard rumors about her pregnancy, we tried to get information about that from her so that we 
could support her, but she would not accept. How can we give counseling in a situation like this one?"

The lack of trust for the teachers in general, including teacher counselors, was also linked to lack of counseling skills of teacher counselors and other factors in the school. The teacher counselors reported that learners' prior experiences of fear or betrayed trust in a school setting, for example, also contributed to a lack of trust between learners and teacher counselors. "How can a learner trust me if he or she knows I will not keep her information confidential?", a teacher counselor from an urban secondary school in Oshana emphasized.

Some learners associated being called to come and see a teacher counselor with having done something wrong and as a result, they rarely went for counseling sessions. If they went, because a teacher counselor insisted, they did not open up or told lies, because of fear that if they told the truth, they would be punished or exposed.

The lack of services was also associated with low incidences of learners seeking counseling. Some learners had challenges beyond the capacity of school counseling. They knew that, except for listening and sympathizing, teacher counselors were not able to help them. In one case in the Kunene region, a learner was earmarked by her parents for marriage as culture dictated. Although she wanted to remain in school and wanted to discuss the issue with the teacher counselor, there was barely anything the teacher counselor could do to stop her family from marrying her off.

\subsubsection{Lack of Suitable Space, Time, Appreciation and Acknowledgment for the Role of Teacher Counselors}

Lack of suitable space and time to do counseling were also key challenges across the sample. A visibly frustrated teacher counselor from a school in Khomas urban area reported the challenge of counseling learners when she did not have space designated for counseling and had a full teaching workload like other teachers. She said, "We are overloaded ... There is no space for counseling. I have to walk through a class with someone who is crying to get to the 'office' at the back of a class which I use for counseling. It is as if counseling is not valued." The growing numbers of learners in schools have led to a situation whereby every space in schools was used for teaching with no private rooms reserved for counseling. Some teachers reported having to listen to learners' problems and attempting to help them under trees or in open spaces in full view of bypassers.

At the time of this research, the work of the teacher counselor was voluntary and done in addition to regular teaching. This seemed to have contributed to the subordinate status given to counseling in many schools. Teacher counselors explained at length the difficulties they experienced trying to be both teachers and counselors. This situation was not only exacerbated by the lack of dedicated space and time for counseling, but also by lack of support from school management, with more emphasis and value being placed on academic subjects than counseling and lack of a common understanding among staff members and learners of the objectives and approaches used in counseling.

"I have 35 periods per week like other teachers. And children cannot stay after school. They will get into trouble with parents for coming home late. They will also miss the group they walk with [It is not safe to walk alone], and some children really come from very far. Sometimes when children have difficulties and find themselves in difficult situations, I do counseling during classes, which means we miss classes." (Teacher counselor, Khomas urban primary school. ).

In the light of these challenges, almost all teacher counselors called for schools to appoint fulltime teacher counselors and/or to reduce the workload of the teacher counselors.

The lack of acknowledgement of the role of teacher counselor was exacerbated by teachers and school management who undermined the work being done by the teacher counselors. A teacher counselor from a secondary school in Kunene concluded that:

“... We are not acknowledged as a body that can make any contributions. You may know about a particular learner's circumstance. The next thing you hear is that the learner has been expelled. They [school management] do not consult us."

\subsubsection{Teacher Counselors Felt Powerless to Protect Learners}

Teacher counselors often felt helpless to intervene in creating a better school environment. They felt powerless to address corporal punishment, bullying, sexual harassment and the use of inappropriate language against learners even though they were aware that these were taking place against existing education policies. Communities, including schools, failed to implement positive ways of behavior modification and continued to cling to punishment as the only way of addressing discipline issues. The school environment plays an important role in the emotional well-being of both learners and teachers [15]. Most of the sample schools were found to be promoting practices that were not only harmful to the emotional well-being of learners, but also go against the current counseling approaches that were supposed to be implemented. They also were contrary to the requirements of the Code of Conduct for the Teaching Services [16]. Corporal punishment, bullying, sexual harassment and inappropriate language used against learners among themselves or by teachers were common in many school environments. In some schools corporal punishment was administered without consideration of the ministerial guidelines and it was accepted as the norm. Researchers noted the helplessness of teacher counselors to act against these practices, even where the education and other policies were clear and known to all role players. Such helplessness was demonstrated by the manner in which principals and teachers were aware of the abolishment of corporal punishment, yet they continued administering it on learners as a disciplinary measure. There were learners bullied by 
other learners and teachers with little action being taken either by school management and/or teacher counselors. Most schools visited lacked characteristics of inclusive, welcoming environments in which learners were supposed to feel embraced. Schools rarely promoted democratic practices as school cultures and structures were adversarial in many ways. These created situations of stress and despair for learners who already came from home that did not offer love and protection.

Teacher counselors were powerless and unable to protect learners against disciplinary committees. The problem was further exacerbated by a lack of coordination between school management and counseling committees. In many cases, teacher counselors felt powerless to protect learners in a confidential manner against disciplinary committees. Teacher counselors did not serve on the disciplinary committees that took decisions about learners' behaviors. There was a common trend of viewing behavioral difficulties in isolation from learners' circumstances. Teacher counselors reported that school management believed that uniform disciplinary measures were "safer" than treating cases on merit, as this system could introduce room for exploitation by learners who did not necessarily need differentiated treatment. The lack of coordinating structures between school management and the counseling committees further exacerbated this problem. This reflected the lack of equity in the system, as well as a lack of institutionalized acknowledgement of counseling in general. This often resulted in a misunderstanding of the teacher counselor's role. In several cases teacher counselors reported being perceived as "protectors" of learners and "promoters of learner misbehavior". A secondary school teacher counselor from Khomas region suggested that "... teacher counselors should at least be given a say in disciplinary hearings. We know of confidential information about learners which, because of confidentiality, we cannot say to anybody."

Teacher counselors were more aware of problems arising from family and other circumstances external to the school system than those arising from within the school. They appeared to be less able and/or willing to identify problems within the school system. However, there were no structures in place for them to infuse their knowledge of learners' psychosocial needs into the school system as school cultures and structures remained rigid and incognizant with the methodologies promoted through the counseling approaches. No wonder they requested that school managers attended counseling trainings as these were offered by senior Ministry of Education officials who have the authority to guide principals.

\subsubsection{Teacher Counselors Struggled to Deal with Cultural Issues}

A number of teacher counselors found it difficult to deal with culturally-related issues. These included lack of support for the concept of counseling from parents, who insisted on the use of corporal punishment; customary practices that compromised schooling and practices relating to death and bereavement. Teacher counselors often found themselves caught between the culture of the surrounding communities, and their own and the government policies. In the Kunene region, respondents were of the opinion that contemporary counseling (used by the Ministry of Education) was far removed from their cultural realities, as one teacher counselor from Kunene explained, "A culture that likes counseling is a culture that consults. But our culture commands. It is not about how you feel, but what your parent decides ... Marriage is not about whom the girl loves, it is about what her father decides. If her father wants her to get married, he gives her to a man to get married even if she is in school."

From this perspective, a teacher counselor could not advise a learner to first complete school and consider marriage afterwards, because the learner was already given to a man as a wife, the husband has the final say over whether or not the particular learner will remain in school.

Similarly, in some cultures, mourning rites following death of a family member were lengthy, extending time a learner will miss on academic responsibilities. Also, in some cultures, death resulted in children being distributed among family members after the death of their parents; in most cases leading to siblings being split, yet the school system rarely recognize such micro-systemic changes as imposing impediments to learning. Once a learner returns to school after a parent's funeral, they are expected to continue as if nothing happened. Teacher counselors would be the only ones trying to support the learner in a system that seem to ignore possible changes in a learner's life.

\subsubsection{Teacher Counselors' need for Training Regarding Legal Issues}

A number of teacher counselors found difficulties dealing with legal issues, particularly related to sexual abuse and rape. The quote below clearly illustrates the dilemma faced by a teacher counselor in Oshana: "I reported a rape case to the police. The accused sued me. And there I was, on my own! We are not protected in such cases?"

Almost in all regions covered by this study, teacher counselors related how they had to go to court to testify in cases without any support from their supervisors.

\subsection{Suggestions for Making Their Job Less Stressful}

When asked for suggestions on how to make their jobs less stressful, teacher counselors made the following recommendations: (a) Each school should have a full-time school counselor and a social worker. In addition to a full-time school counselor, all other teachers should be sensitized to get involved so that every teacher can serve as support for learners in need of emotional support. (b) Workshops should be held a week before school starts, or a week after school closes so that teacher counselors attend without fearing to miss classes. (c) Government should appoint a full-time school counselor for each school, but teacher counselors should not be done away with. They should support the school counselor, but not carry the whole burden of counseling. (e) Principals should attend 
counseling training so that they understand and support teacher counselors better. Training of school management in counseling will ensure that in future, management will take counseling more seriously. (f) Counseling training should be integrated in teacher-education curriculum to avoid long absences from work for counseling workshops. (g) Regular visits and information from the Regional School Counselors. "Sometimes we feel isolated. When they [Regional School Counselors] come, they should not only come and look into files. They should give mentoring support", said a teacher counselor from a Khomas rural primary school.

Teacher-counselors' recommendations revealed their willingness to continue counseling learners, but with support from a dedicated staff members (school counselors) whose core business will be counseling learners and providing them with skills to prevent and cope with difficulties when they occur. Burn-out was obvious in some cases.

\section{Discussion}

There was a significant number of learners in Namibian schools whose psychosocial circumstances were dire. They needed psychosocial support. Instead of appointing school counselors, the Ministry of Education opted to request schools to appoint teacher counselors to render this support. Teacher counselors were teachers who were entrusted with the responsibility of rendering lay counseling services to learners in the school setting. Some teachers volunteered to become teacher counselors, others were elected by their fellow teachers, and others were nominated by their principals because they had lighter workloads or were doing work that was related to counseling.

The majority of the teacher counselors in the sample were happy with the work of counseling learners despite the many challenges they were facing including lack of incentives and support. Many teacher counselors provided understanding and compassion to learners under very difficult conditions. The training in counseling skills had successfully sensitized a significant number of teacher counselors to the psychosocial needs of learners and basic methodologies to address such needs. It has also managed to increase their empathy for learners. The presence of teacher counselors at schools made a positive difference to many learners, some for whom the teacher counselor was the only adult who acknowledged their difficulties and valued them as human beings. Many teacher counselors, as a direct consequence of the training, were motivated to make social work type interventions and act as advocates for learners. Little (if any) real counseling took place; most interventions were practical and/or focused on motivating learners not to become disheartened. In some cases, debriefing took place but was rarely followed by professional counseling needed to help leaners overcome traumas. Given the level of training as well as the circumstances, this was realistic and practicable.

The teacher counselors were faced with a number of challenges. The obvious challenge was that they needed more and better training in counseling. They were not qualified counselors, but ordinary teachers who did lay counseling as para-professionals. Areas in which teacher counselors expressed a need for further training included addressing sensitive issues (e.g. grief and loss, HIV/AIDS and the many issues around sexuality), and how to work with learners in different developmental stages. The majority of teacher counselors was unclear about the scope of practice, and struggled with ethical considerations and legal issues. Difficulties around sexuality, and problems with other teachers (lack of support and viewing teacher counselors as watchdogs for misbehaving learners), were problems raised by nearly all teacher counselors.

Despite the availability of a reference guide for domestic violence and sexual abuse, teacher counselors did not know how to handle cases of domestic violence, sexual abuse, rape, and incest. Rape and sexual abuse were particularly problematic issues when teacher counselors lived in the same community as learners. Many of the teacher counselors also had problems dealing with cultural issues (for example, early marriages jeopardizing learners' access to education; distribution of orphans in families; difficulties of monitoring how OVC lived in host families; parental preference of corporal punishment as opposed to the counseling approaches, etc.).

Because of lack of proper counseling skills coupled with the culture of not opening up to outsiders, teacher counselors found it difficult to counsel learners. Learners did not trust them and therefore did not open up. Moreover, lack of trust was a result of prior experiences of betrayed trust. Learners were suspicious that teacher counselors would reveal their problems to others outside the trust relationship. They also thought that they would be punished if they opened up.

Because of the fact that teacher counselors were appointed on a voluntary basis, they had to do their counseling work in addition to their normal teaching loads, and received no or formal acknowledgement, remuneration or incentives for their counseling roles, they did not have adequate time available to counsel learners. In addition, schools did not provide space where teacher counselors counsel learners. Teacher counselors made use of any available space such as under trees, back of the class, staff room, etc. Obviously, such spaces could have negative effects on the success of counseling rendered.

The study also revealed that teacher counselors were struggling to intervene in creating a better school environment for learners. Corporal punishment, bullying, sexual harassment and inappropriate language used against learners among themselves (and sometimes these continued in homes) or by teachers were common in many school environments; and teacher counselors, albeit being aware that these inhumane treatments were taking place and they were unhappy about them, they felt powerless. They did not have the power to influence change in the behavior of their fellow teachers and their principals.

Similarly, teacher counselors were aware of the learners' problems arising from families and other circumstances external to the school system, but they felt that there was 
nothing they could do about. For example, it was difficult for them to discourage forced and early marriage among learners.

\section{Conclusion}

The model of having teacher counselors at each school in Namibia was promising. Many teacher counselors provided understanding and compassion, despite significant resource constraints and limited support. The presence of teacher counselors at schools made a positive difference. Problematic was the fact that teacher counselors were appointed on a voluntary basis, had to do their counseling work in addition to their normal teaching load, and received no remuneration, incentives or formal acknowledgement for their work. In addition they were facing challenges including unavailability of appropriate space and time to counsel learners. The teacher counselors recommended, inter alia, that full-time school counselors or teacher counselors be appointed, and that principals should attend counseling training so that they understand and support teacher counselors.

The researchers are happy to report that, following the report of this research, the Ministry of Education in Namibia has implemented the appointment of full-time Life Skills teachers who are now carrying the primary responsibility of counseling while the teacher counselors are rendering additional support. It will be worth exploring how these newly appointed Life Skills teachers were perceiving their roles and how teacher counselors view their support roles.

\section{References}

[1] Ministry of Education. (2008). Education sector policy for orphans and vulnerable children. Windhoek: Ministry of Education

[2] Ministry of Education (2005). National standards and performance indicators for schools in Namibia. Windhoek: Ministry of Education.

[3] Ashton, Haihambo, Nuujoma-Kalomo, 2007. An assessment of the quality of services offered to orphans and vulnerable children in Namibian secondary schools. Windhoek: UCCB.
[4] Whiston, S. C., \& Sexton,T. L. (1998). A review of school counseling outcome research: Implications for practice. Journal of counseling and development, 76, 412-426.

[5] Howieson, C. \& Semple, S. (2000). The evaluation of guidance: Listening to pupils' views.' British journal of guidance \& counselling, 28(3), 373-388.

[6] Cooper, M., Hough, M. \& Loynd, C. (2005). Scottish secondary school teachers' attitudes towards, and conceptualisations of counselling. British journal of guidance and counselling, 33 (2), 199-211.

[7] Sun, J., \& Stewart, D. E. (2007). Development of population-based resilience measures in primary school setting. Health education, 107(6), 575 - 599.

[8] Yuksel-Sahin, F. (2009). The evaluation of counseling and guidance services based on teacher views and their prediction based on some variables. International journal of instruction, January, 2 (1), $59-76$.

[9] Paisley, P. O. \& McMahon, H. G. (2001). School counseling for the 21st century: Challenges and opportunities. Professional school counseling, 5, 106-115.

[10] Sears, S.J. \& Granello, D.H. (2002). School counseling now and in the future: A reaction. Professional school counseling, 5(3), 164-171.

[11] Rayle, A. D. (2006). Do school counselors matter? Mattering as a moderator between job stress and job satisfaction. Professional school counseling, 9, 206-215.

[12] [Mushaandja, J. (2013). The limits of monetary incentives in workplaces in Namibia. International journal of social studies tomorrow, 2 (3). Retrieved from: http://www.ijsst.com/vol2 issue3.php[13] University of Namibia. (2012). Faculty of Education Prospectus. Windhoek: University of Namibia.

[13] University of Namibia. (2012). Faculty of Education Prospectus. Windhoek: University of Namibia.

[14] Patton, M. Q. (2002). Qualitative research \& evaluation methods (3rd ed.). London: Sage Publications.

[15] Armstrong, T. (2006). The Best Schools: How Human Development Research Should Inform Educational Practice. Alexandria: Association for Supervision and Curriculum Development.

[16] Ministry of Education (2004). Amendment of regulations made under Education Act, No. 16 of 2001: Code of conduct for the teaching services. Windhoek: Ministry of Education. 